\title{
O trabalho em equipe desenvolvido pelo cirurgião-dentista na Estratégia Saúde da Família: expectativas, desafios e precariedades
}

\author{
The teamwork developed by the surgeon dentist in the Family Health \\ Strategy: expectations, challenges and precariousness \\ El trabajo en equipo desarrollado por el dentista en la Estrategia de \\ Salud Familiar: expectativas, desafíos y debilidades \\ Rossana Mota Costa ${ }^{1 \star}$, Antonio Medeiros Junior ${ }^{2}$, Íris do Céu Clara Costa ${ }^{3}$, \\ Isauremi Vieira de Assunção Pinheiro
}

Palavras-chave: Programa Saúde da Família Condições de Trabalho Odontologia do Trabalho Family Health Strategy

Labor Conditions Occupational Dentistry

\section{Resumo}

Este estudo objetivou conhecer a integração do cirurgião-dentista (CD) com os demais profissionais pertencentes à Estratégia Saúde da Família (ESF), bem como identificar o seu processo de trabalho dentro dessa equipe. 0 estudo desenvolveu-se no município de Parnamirim-RN, e dele participaram todos os CDs que atuam na ESF do município, num total de 30 profissionais. 0 Instrumento de coleta de dados utilizado foi um questionário semiestruturado e a variável dependente foi 0 trabalho em equipe. Os dados foram analisados por meio da estatística descritiva (distribuições absolutas e percentuais). Observou-se que os CDs não participam de forma integrada na equipe. A articulação das ações entre os membros da equipe não acontece de forma habitual e sistemática, como parte integrante de seu processo de trabalho $(56,7 \%)$. Os profissionais de maneira geral mostraram-se insatisfeitos no desempenho de suas funções (63,3\%). Sugere-se uma reflexão no tocante ao desenvolvimento do processo de trabalho em equipe com a participação efetiva do CD.

\section{Abstract}

This study aimed to analyze the integration of the surgeon-dentist (SD) with other professionals belonging to the Family Health Strategy (FHS), as well as identify the work process within this team. The study was developed in the municipality of Parnamirim, State of Rio Grande do Norte, where all the dentists - in a total of 30, that work in the FHS took part in the survey. A semi-structured questionnaire was used for data collection. Teamwork was taken as dependent variable. Data were analyzed by descriptive statistics: absolute and percentage distributions. It was possible to observe that the dentists do not participate in an integrated way in the team. Joint actions among team members do not happen on a regular, systematic basis, as part of their work process (56.7\%). The professionals, in general, are dissatisfied with the performance of their duties (63.3\%). A reflection on the development of teamwork process in the FHS is needed.

\footnotetext{
Universidade Federal do Rio Grande do Norte (UFRN). rossana_mota@hotmail.com

${ }^{2}$ Universidade Federal do Rio Grande do Norte (UFRN). amjunior@ufrnet.br

${ }^{3}$ Universidade Federal do Rio Grande do Norte (UFRN). iris_odontoufrn@yahoo.com.br

${ }^{4}$ Universidade Federal do Rio Grande do Norte (UFRN). isauremi@ig.com.br

*Autor correspondente.

Fonte de financiamento: nenhuma.

Conflito de interesses: declaram não haver.

Recebido em: 08/11/2011

Aprovado em: 03/07/2012
} 
Palabras clave:

Programa de Salud Familiar

Condiciones de Trabajo

Odontología del Trabajo

\section{Resumen}

El objetivo de este estudio fue caracterizar la integración entre el dentista y los demás profesionales pertenecientes a la Estrategia de Salud Familiar (ESF) e identificar su proceso de trabajo dentro de ese equipo. Participaron de este estudio los 30 profesionales dentistas que trabajan en la ESF del municipio de Parnamirim-RN. Los datos se recolectaron con un cuestionario semi-estructurado, siendo el trabajo en equipo la variable dependiente, y fueron analizados mediante estadística descriptiva (distribuciones absolutas y porcentuales). Se observó que los dentistas no participaban en un equipo integrado. La articulación de las actividades entre los miembros del equipo no ocurrió de forma habitual y sistemática, como parte integrante de su proceso de trabajo $(56,7 \%)$. De manera general, los profesionales se mostraron insatisfechos con el desempeño de sus funciones $(63,3 \%)$. Se sugiere una reflexión con relación al desarrollo del proceso de trabajo en equipo, con una efectiva participación de los dentistas.

\section{Introdução}

A Estratégia Saúde da Família (ESF) busca romper com o modelo de saúde vigente, o modelo médico-centrado, com ênfase na doença e no ato prescritivo. Parte de uma concepção ampliada de saúde, na qual esta é vista como resultante das condiçóes de vida em que o indivíduo está inserido. Tem a família como o núcleo central da atenção, trabalha a humanização da assistência, população adstrita e a noção de responsabilidade epidemiológica sobre o seu território de atuação. Portanto, deve constituir-se como primeiro contato da população com o serviço de saúde na atenção básica e através de todos os profissionais nela inseridos, tornar-se responsável por sua população adstrita de forma integral e resolutiva, assim como, instituir práticas que rompam com o modelo de atenção hegemônico e assistência hospitalar.

Dessa forma, a família assume um papel fundamental para o entendimento e desenvolvimento do processo de trabalho da ESF, uma vez que a abordagem familiar fortalecerá a atuaçáo da equipe multiprofissional através de uma intervenção mais integral e mais humana.

Torna-se pois, imprescindível que antes de qualquer proposta de trabalho com as famílias, o profissional procure conhecer cada um dos membros, respeitar a organizaçáo familiar, o modo como cada membro enfrenta seus problemas e adaptar-se à forma de comunicação daquela família. Os resultados desta integração entre profissional e família serão observados no dia a dia das equipes e no resultado de açóes que possam ser realizadas pelo profissional ${ }^{1}$.

O trabalho em equipe é então destacado no conjunto das características da ESF como um dos pressupostos mais importantes para a reorganizaçáo do processo de trabalho enquanto possibilidade de uma abordagem mais integral e resolutiva, bem como, deve ser compartilhado com resultados assumidos e discutidos por cada membro da equipe ${ }^{2}$. Profissionais satisfeitos no desempenho de suas funçóes são profissionais motivados, empenhados em melhorar a qualidade do serviço prestado, bem como, a autoreflexão sobre seu processo de trabalho permitirá a reorientação das ações desenvolvidas.

\section{0 processo de trabalho em saúde e sua dimensão cuidadora}

No conjunto dos serviços de saúde ofertados no Sistema Único de Saúde (SUS), emerge o trabalho, ou o que se quer do processo de trabalho das equipes de saúde da família, reafirmando o princípio da integralidade, eixo condutor das ações na APS no sentido do profissional ver o usuário no momento da realizaçáo do cuidado, de forma integral e não segmentada, buscando a resolutividade de seus problemas em todos os níveis de atenção que sua necessidade mereça ${ }^{2}$.

Quanto ao formato de trabalho da ESF, Peduzzi ${ }^{3}$ observa uma distinção entre as duas noçóes que permeiam a ideia do trabalho em equipe. São elas: a equipe como agrupamento de profissionais e a equipe como integração de trabalhos. A primeira é caracterizada pela fragmentação e justaposição de açóes e a segunda pela articulação consoante à proposta da integralidade das açôes de saúde. Em ambas estão presentes diferenças técnicas, tensōes entre as diversas concepções e exercícios de autonomia técnica. Porém, cabe ao profissional contornar estas situaçóes tornando o trabalho em equipe dinâmico, resolutivo e motivador, possibilitando a articulação das ações, a interação comunicativa dos profissionais e a superaçáo do isolamento dos saberes.

De acordo com Araújo e Rocha ${ }^{4}$ o trabalho em equipe no contexto da ESF ganha uma nova dimensão no sentido da divisão de responsabilidades e do cuidado entre os membros da equipe, na qual todos participam com suas especificidades, contribuindo para a qualidade da prestaçáo das açôes de saúde. A concepção integral do cuidado favorece a ação interdisciplinar nas práticas em que a valorização das diversas disciplinas contribui para uma abordagem ampla e resolutiva do cuidado. 
De acordo com Souza ${ }^{5}$ a saúde é um objeto complexo, que necessita de uma abordagem que supere a organização do trabalho baseada em disciplinas autônomas ou estanques. Portanto, o ideal seria um trabalho desenvolvido através da integração das disciplinas e estas operando de forma compartilhada, ou seja, por via transdisciplinar. A transdisciplinaridade por sua vez, baseia-se em um sistema de vários níveis com objetivos diversificados e sua coordenação é assegurada por referência a uma finalidade comum, com tendência à horizontalização das relações.

É fundamental a compreensão de que apesar do trabalho em saúde estar pautado em normas institucionais, como no caso da ESF, cada profissional tem a autonomia de desenvolver o cuidado dentro do espaço de sua micropolítica, segundo expressão de Franco e Merhy ${ }^{6}$ entendida aqui como o seu agir cotidiano, de forma dinâmica e criativa ou simplesmente de forma prescritiva e mecanizada.

Werneck e Ferreira ${ }^{7}$ reiteram que a tecnologia, respeitando princípios éticos e procurando promover a cidadania, deveria ser percebida a partir de diretrizes em que trabalhador, consumidor, equipamentos e modo de produzir interajam de forma harmônica em função de objetivos que contemplem qualidade de vida no trabalho e qualidade de vida das pessoas.

O profissional deve ter em mente que cada indivíduo por ele assistido é único e com uma história própria, também única, não cabendo normas ou formas rígidas de atendimento. Deve considerar ainda que uma equipe é composta por pessoas que trazem particularidades e interesses próprios. Essas características exercem influência sobre o processo de trabalho, uma vez que estáo presentes no agir cotidiano de cada profissional e portanto, passível de erros e acertos dependendo da forma como sáo conduzidas.

Nesse sentido, Pires ${ }^{8}$ afirma que o trabalho em saúde é um trabalho essencial para a vida humana. Em sua maioria esse trabalho é coletivo, realizado por diversos profissionais de saúde e outros grupos trabalhadores, desenvolvendo uma série de atividades necessárias para a manutenção da estrutura institucional, assim como, os profissionais envolvidos dominam os conhecimentos para o exercício das atividades específicas de sua profissão.

Mattos $^{9}$ aponta como um dos problemas do trabalho em saúde as dificuldades na passagem do enfoque político para o assistencial, expressando-se na identidade dos atores sociais e nos seus projetos. Esta situação impóe desafios para a gestão do trabalho cotidiano das equipes enquanto recriação de projetos coletivamente sustentados que necessitam estar associados à recriação de novos sujeitos sociais defensores de certas crenças e valores.

Vilarinho et al. ${ }^{10}$ em seu estudo com CDs integrantes da ESF em Teresina - PI afirmam que a existência de grande demanda reprimida, necessidades acumuladas, entre outros, impede que o modelo tradicional de atendimento seja substituído totalmente por aquele centrado nos princípios doutrinários e organizativos do SUS, visto que os procedimentos curativos continuam sendo predominantes.

Cotta $^{11}$ em pesquisa realizada no município de Teixeiras - MG, afirmam que houve uma transformação progressiva de cenário após a implantação da ESF. Os resultados encontrados corroboram pesquisas anteriores quanto à constatação das mudanças ocorridas ao longo da última década e sua importância à definição de políticas relacionadas ao trabalho, educação e às finanças públicas. Os atuais problemas dos profissionais e gestores sanitários e seus novos desafios a enfrentar, confirmam a necessidade da formação de trabalhadores com níveis mais elevados de educação geral e qualificação profissional e portanto, mais capacitados a atuar em saúde coletiva e comunitária.

Araújo e Dimenstein ${ }^{12}$ em investigação sobre a atuação de CDs inseridos na ESF de municípios do Rio Grande do Norte, encontraram que os profissionais têm perfil voltado para a clínica, aspecto que está relacionado à sua formação acadêmica, na qual se vê a reprodução de práticas tradicionais, fragmentadas e isoladas, havendo portanto a necessidade de motivar os profissionais a refletirem sobre suas práticas, tendo como medida inicial o investimento e estímulo à educação permanente e um monitoramento e avaliação das açóes por eles desenvolvidas.

Facó et al. ${ }^{13}$ em pesquisa realizada com CDs da ESF no Ceará, afirmam que duas questôes afligem os profissionais a ponto de intervir em suas práticas: padróes salariais bastante defasados e a falta de vínculo empregatício que desestimulam os profissionais à se dedicarem. Outro ponto também importante, segundo os autores, é a formação acadêmica que deixa a desejar quando se fala em Saúde Coletiva, uma vez que a Universidade que constitui o centro formador por excelência de recursos humanos odontológicos não proporciona elementos técnicos que permitam aos estudantes compreender as realidades sociais da profissáo.

Rodrigues e Araújo ${ }^{14}$ pesquisaram sobre os profissionais de saúde bucal dos serviços públicos do Rio Grande do Norte e observaram que o perfil dos profissionais de saúde bucal necessita de uma adequação para atender aos princípios do SUS e da ESF, visto que a maioria é constituída por especialistas que não exercem tais habilidades e quando as executam, fazem de forma fragmentada, com base no paradigma flexneriano, ou seja, no modelo curativo.

Percebe-se a necessidade de mudanças de atitude dos profissionais, em especial os da saúde bucal que atuam na ESF, para que haja transformaçóes efetivas no processo de trabalho, no ato de cuidar, buscando-se progressivamente 
uma nova forma de realizá-lo, agregando novos valores, ferramentas e tecnologias, constituindo-se assim um novo padrão de saúde bucal na comunidade.

Procurar estabelecer uma conexão com os diferentes processos de trabalho - tendo como base algum conhecimento acerca do trabalho do outro, valorizando e estimulando a participação deste na produção do cuidado - constitui a essência do trabalho em equipe. Para isto, faz-se necessário identificar conflitos, construir consensos quanto às metas a serem alcançadas, assim como, ter clareza sobre quais resultados a equipe espera e a maneira mais rápida e adequada de atingi-los.

Mudanças nas relações de trabalho não acontecerão de maneira rápida. Os profissionais que compóem as equipes, principalmente o cirurgiáo-dentista, vêm de uma prática na qual predomina o tratamento curativo-restaurador ou mutilador sobre as demais atividades. $\mathrm{O}$ médico, por sua vez, tradicionalmente é reconhecido como figura central e predominante nos serviços de saúde o que torna as relaçóes de trabalho hierarquizadas e verticalizadas.

Este cenário já é um velho conhecido de todos os trabalhadores, porém torna-se fundamental uma reflexão sobre a forma como o processo de trabalho está sendo conduzido e os resultados alcançados versus resultados esperados.

Volschan et al. ${ }^{15}$ reiteram o fato da formação acadêmica do CD estar voltada para a segmentação, especialidades, curativismo, não preparando o profissional para o coletivo, ao mesmo tempo em que mostram que a formação centrada no paradigma científico vem sendo revista, de modo a resgatar o caráter coletivo da prática odontológica. Desta forma, os futuros profissionais poderão sair das universidades preparados para desempenhar suas funçóes neste novo modelo de atenção, beneficiando sua relaçáo com o paciente, bem como com profissionais de outras áreas com quem irão se relacionar.

Deve-se estar atento, portanto, para o ato de realização do cuidado em saúde, o momento que realmente faz a diferença entre um processo centrado na lógica instrumental ou tecnologias duras e o processo terapêutico mais relacional, centrado nas tecnologias leves. Mesmo se utilizando da lógica instrumental, o profissional deve reconhecer que aquele usuário traz consigo uma origem social, relaçôes familiares e ambientais que expressam sua história e portanto deve ser compreendido como tal, um sujeito com individualidade e subjetividade próprias. A qualidade no sistema de atenção à saúde poderá ser alcançada se houver uma conformaçáo adequada da relação entre estas tecnologias.

Este estudo tem como objetivo abordar o papel do cirurgião-dentista (CD) na Estratégia Saúde da Família (ESF) e se propóe a identificar o trabalho desenvolvido por ele junto a equipe, bem como verificar o seu grau de satisfaçáo no sentido de poder contribuir para a reorientação de suas práticas e adequaçáo de seu perfil, buscando a melhoria da qualidade do serviço.

\section{Material e métodos}

Trata-se de um estudo do tipo transversal realizado no município de Parnamirim-RN, localizado na região da Grande Natal, com uma populaçáo estimada pelo IBGE em 2003 de 143.598 habitantes, contando com a seguinte rede de saúde: 22 Unidades Básicas de Saúde (UBS), 42 Equipes da ESF implantadas, incluindo 31 equipes de saúde bucal.

$\mathrm{O}$ instrumento de coleta de dados utilizado foi um questionário semiestruturado. Participaram da pesquisa todos os CDs que atuam na ESF do município, num total de 30 participantes, sendo utilizada a amostragem não probabilística.

Como critérios de inclusão, foram levados em consideração:

- ser dentista ativo da ESF do município;

- aceitar participar da pesquisa.

Foram excluídos da pesquisa os demais dentistas que trabalhavam na atenção básica do município (sem ESF implantada).

As variáveis estudadas foram: trabalho em equipe, grau de satisfação e tempo de experiência na ESF.

$\mathrm{O}$ projeto foi submetido à apreciação e aprovação do Comitê de Ética em Pesquisa da UFRN, com número de parecer 052/08 de acordo com a Resoluçáo 196/96 do Conselho Nacional de Saúde.

Previamente à realização da pesquisa, foi feito um pré-teste objetivando identificar problemas e dificuldades em relação aos procedimentos metodológicos inicialmente planejados. Participaram 5 cirurgiôes-dentistas que não fizeram parte da pesquisa, não tendo sido necessária nenhuma modificação no instrumento de coleta de dados.

A coleta de dados foi realizada por um único pesquisador em visita a todas as UBS com ESF implantada, durante os meses de setembro, outubro e novembro de 2008.

Depois da autorização da Secretaria de Saúde do município para a realizaçáo da pesquisa e para o acesso às unidades de saúde, foi aplicado um questionário semiestruturado como instrumento de coleta dos dados.

Os dados coletados através do questionário foram categorizados e posteriormente, utilizou-se o Software SPSS/13.0 que permitiu a realizaçáo de uma análise descritiva apresentada em números absolutos e percentuais. 


\section{Resultados e discussão}

Tratando-se de treinamento introdutório para ingresso na ESF, 96,7\% relataram que não realizaram capacitação antes de ingressarem porém, após o ingresso, 66,7\% fizeram algum curso para capacitá-los, alguns promovidos pela própria Secretaria de Saúde do município (como o introdutório) e outros por iniciativa própria.

$\mathrm{Na}$ verdade, o introdutório, como o nome mesmo diz, deve ser uma introdução à ESF, no qual os profissionais irão compreender a proposta de trabalho da ESF, desenvolver uma visão ampliada e diferenciada do processo saúde-doença e da abordagem familiar, tâo importante no desenvolvimento do processo de trabalho na ESF.

Mais do que uma simples orientaçáo inicial torna-se fundamental para atualização de profissionais originários de formaçáo específica, um processo de educação permanente, sistematizado, capaz de corrigir e/ou aprimorar habilidades ${ }^{11}$.

No tocante a outras atividades desenvolvidas na odontologia, paralelamente ao trabalho na ESF, 96,7\% dos CDs disseram que trabalham também em outros setores públicos ou privados, apesar das 40 horas semanais exigidas pelo Ministério da Saúde. Apenas uma pequena parcela, $3,3 \%$, disse trabalhar exclusivamente na ESF. Destes $96,7 \%$ que têm algum vínculo empregatício além da ESF, 55\% possuem vínculo no setor público e privado simultaneamente.

É significante o número de profissionais que possuem outros vínculos empregatícios além da ESF apesar das oito horas diárias exigidas pelo Ministério da Saúde. Sabe-se que a ESF náo oferece estabilidade ao trabalhador, pois a forma de contratação em alguns municípios é precária, sem seleção ou concurso público e acredita-se que, provavelmente, esta precarização do vínculo profissional faz com que ele procure atividades em outros campos de atuação ou atue em sua área em outras instituiçóes, até como forma de complementação salarial.

Em pesquisa realizada em âmbito nacional sobre a modalidade de contratação de pessoal na ESF, comprovou-se que as contrataçóes são realizadas em grande parte pelas prefeituras municipais, sendo os contratos temporários ou prestaçôes de serviço as principais formas de contratação estabelecidas com os profissionais ${ }^{16}$. Aliás, diversas pesquisas mostram que no SUS, assim como nos demais setores do mercado de trabalho nacional, proliferam os contratos informais. Desta forma, esses profissionais permanecem à mercê da instabilidade político-partidária e das diferenças entre governos que se sucedem no poder, táo presentes na realidade dos municípios brasileiros ${ }^{11}$. Convém salientar que esta instabilidade das relaçóes de trabalho pode resultar em uma série de contratempos, tais como: falta de compromisso com o serviço, baixa qualidade dos servicos ofertados, práticas clientelistas, desmotivação, falta de responsabilidade na execução das atividades, entre outras.

O município traz consigo a particularidade de ter na ESF a porta de entrada para $70 \%$ da atenção básica à saúde, assim como grande parte dos municípios brasileiros. Esta característica traz uma série de pontos positivos, como desafogamento da alta complexidade, resolutividade de açóes, trabalho com população adstrita proporcionando cobertura vacinal, controle e prevenção de doenças como diabetes, hipertensão, câncer de colo uterino, entre outras.

Desta forma, as barreiras geográficas para acesso a UBS, como: distância, falta de transporte, difícil acesso, etc., não são sentidas pela população em grande parte dos locais de implantaçáo das UBS, em virtude destas localizarem-se em perímetro urbano, o que facilita o acesso da populaçáo ao serviço.

Com relação às avaliaçóes e planejamento das açóes, $60 \%$ dos CDs afirmaram que frequentemente participam das reunióes em equipe, $23,3 \%$ disseram que só participam ocasionalmente, $6,7 \%$ disseram que não participam destas reuniōes e $10 \%$ relataram que a equipe não se reúne, de acordo com a Figura 1.

Porém, quando se questionou sobre a periodicidade destas reuniôes $33,3 \%$ disseram que não há periodicidade definida, $30 \%$ responderam que só se reúnem de acordo com a necessidade da equipe e os demais responderam que se reúnem semanal, mensal ou quinzenalmente, como mostra a Figura 2.

De acordo com os resultados obtidos, pode-se deduzir que as reunióes de equipe não acontecem de forma habitual, não fazendo parte do processo de trabalho dos $\mathrm{CDs}$ de maneira sistemática e, como consequência, o planejamento das açôes a serem trabalhadas fica comprometido. O CD é apenas comunicado das decisóes tomadas por outros membros da equipe ou pela administração da UBS, ou vice-versa, configurando-se, desta forma, um modelo vertical de trabalho.

Sabe-se que este momento de integração da equipe é indispensável para esclarecimentos de dúvidas e resoluções das questôes que ficam pendentes no dia a dia. Quando estas reunióes acontecem sem uma determinada periodicidade, os problemas tendem a acumular-se, comprometendo sua resolução e o entrosamento de toda a equipe.

Enquanto os profissionais se isolarem, por corporativismo, arrogância, insegurança ou ignorância, enquanto não constituírem uma integração de fato entre si, trocando conhecimentos e articulando um campo de produçáo do cuidado, torna-se dificíl a ocorrência de efetivo trabalho em equipe. Os profissionais podem até estar juntos, na UBS, na visita domiciliar ou nas demais atividades externas que exigem certo grau de convivência, mas o aprisionamento do processo de trabalho a estruturas rígidas do conhecimento técnico-estruturado torna-o morto ${ }^{17}$. 
Os $\mathrm{CDs}$ foram questionados em relação às atividades desenvolvidas por eles em parceria com os demais profissionais e integrados com a comunidade adstrita. Foram elencadas várias atividades que são desenvolvidas dentro e fora da UBS, de acordo com a Figura 3.

Observa-se a tímida realização de atividades desenvolvidas em equipe pelo CD. Tanto as atividades na comunidade quanto as realizadas na UBS, ele as realiza apenas ocasionalmente em equipe, o que torna necessário que se reflita quanto à forma de desenvolvimento do trabalho em equipe, no sentido dos profissionais conseguirem estabelecer de fato, relaçóes afetivas, técnicas e científicas que não se limitem apenas à troca de informaçóes.

As visitas domiciliares são realizadas mais ocasionalmente na presença dos demais membros da equipe, tais como, agentes comunitários de saúde (ACS), médico, enfermeira, etc., ou não são realizadas. $\mathrm{O}$ fato de fazer ou não visitas domiciliares não implica, necessariamente, em mudança de prática. Diante desta constatação, poderíamos indagar: o dentista sabe de fato o seu papel dentro do ambiente familiar ou quando realiza a visita domiciliar ou ele participa apenas como mero acompanhante? Deve-se ter em mente a visita domiciliar como uma oportunidade para estreitamento de laços entre profissional/profissional e profissional/usuário, a resolutividade de algum fato que esteja causando sofrimento ao paciente impossibilitado de comparecer à UBS, o desenvolvimento de vínculo e a produçáo de cuidado. Esse momento deveria ser muito bem aproveitado por todos os membros das equipes da ESF.

Para conseguir avanços no modelo assistencial, principalmente no que se refere à saúde bucal, faz-se necessária a articulaçáo de diversos setores dentro do município com a finalidade de implementar políticas públicas saudáveis, que deem respostas concretas às necessidades da população. Além disso, é necessário investimento por parte dos municípios na formação profissional através de cursos de educação permanente. Faz-se necessário também que os profissionais tenham relaçóes de trabalho estáveis para um melhor desempenho de suas funções.

Questionou-se aos CDs o grau de satisfação com relação a suas funçôes, como mostra a Figura 4, vê-se que apenas uma pequena parte destes profissionais mostrou-se satisfeita $(23,3 \%)$, enquanto $63,3 \%$ afirmaram que a satisfação poderia ser melhor em alguns aspectos. Os aspectos referenciados pelos profissionais no presente estudo, diz respeito a: estabilidade no emprego, formas de contratação e remuneração salarial.

Da mesma forma, perguntou-se o grau de satisfaçáo dos profissionais com relação à estratégia saúde da família como um todo e $40 \%$ relataram que estavam satisfeitos, porém $50 \%$ informaram que a satisfaçáo poderia ser melhor em alguns aspectos, 6,7\% afirmaram estar pouco satisfeitos e 3,3\% desestimulados, segundo a Figura 5.

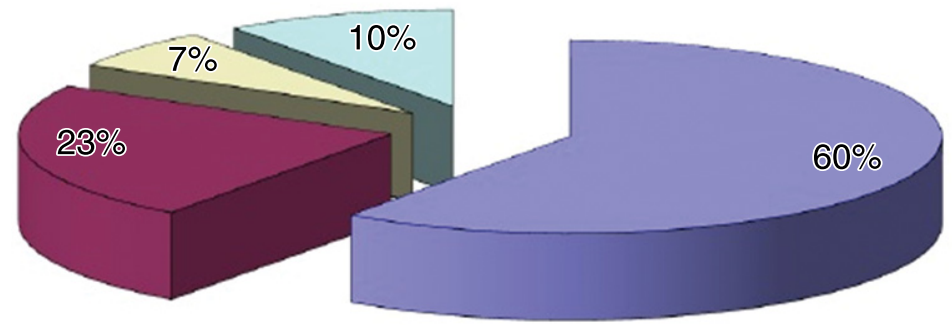

Frequentemente

Ocasionalmente

Não participa

Equipe não se reúne

Figura 1. Resposta em percentual sobre a participação dos CDs no planejamento e avaliação de ações realizadas pela equipe da ESF.

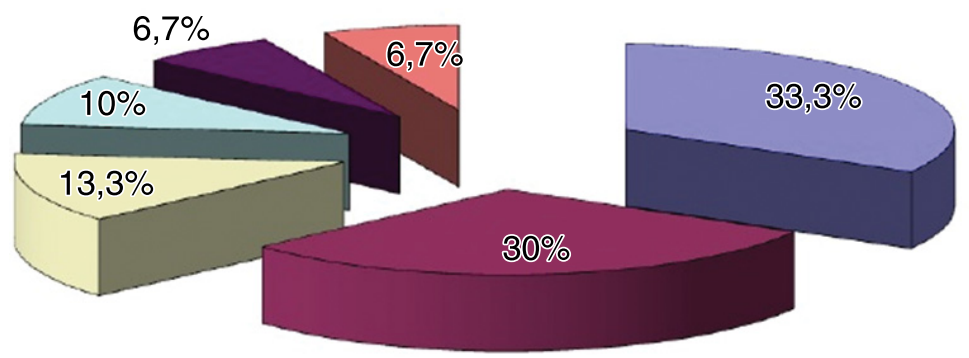

Não tem periodicidade definida

$\square$ De acordo com a necessidade da equipe

Equipe não se reúne

Semanalmente

Quinzenalmente

Mensalmente

Figura 2. Resposta dos CDs em percentual quanto à periodicidade de reuniões em equipe. 
Também foi perguntado se houve melhoria na assistência odontológica após a inclusão do CD na ESF e 100\% responderam que sim, corroborando com os achados de Souza ${ }^{5}$, em que a totalidade dos entrevistados afirmou que ocorreram avanços no modelo assistencial em saúde bucal após esta inclusão.

O campo de trabalho do $\mathrm{CD}$, após sua inclusão na ESF, abriu-se consideravelmente e espaços profissionais vêm surgindo ao longo destes 8 anos de implantação de equipes de saúde bucal na ESF, assim como, através da Política Nacional de Saúde Bucal e do Programa Brasil Sorridente.

Necessita-se, porém, avançar no tocante ao enfrentamento dos fatores considerados nós críticos da ESF, tais como: a forma de contratação e o perfil das equipes; a estabilidade funcional; as mudanças na formação profissional em saúde e no processo de qualificação profissional das equipes; a estrutura organizacional e de gestão na ESF e do SUS; as profundas iniquidades sociais presentes na sociedade brasileira; a questão do acesso e a integralidade da atenção ao usuário ainda comprometida; a questáo do financiamento do SUS; a equiparação de salários entre os demais profissionais de saúde da equipe e a implantação de um Plano de Carreira, Cargos e Salários que possibilite a ascensão profissional e a satisfação pessoal no trabalho. Enfim, melhorias abrangentes nas condiçóes de vida e trabalho para que os profissionais, os trabalhadores da saúde e principalmente os CDs, sujeitos deste estudo, se sintam seguros e motivados para desenvolver suas competências e habilidades de forma mais completa e em consonância com os princípios doutrinários e organizativos do SUS.

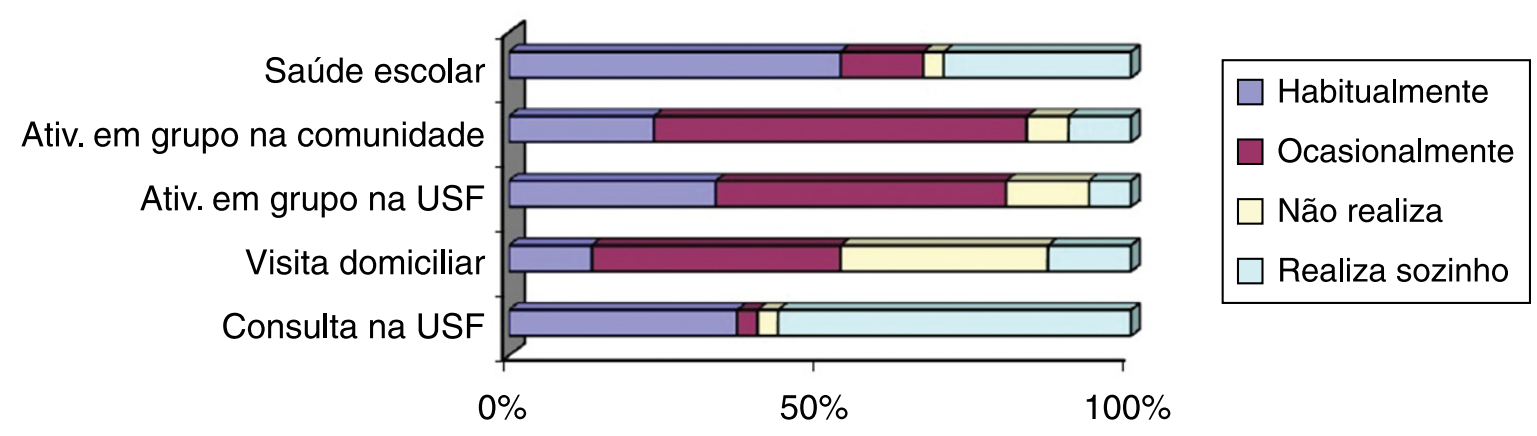

Figura 3. Percentual das citações dos CDs relativas às atividades desenvolvidas em parceria com os demais profissionais.

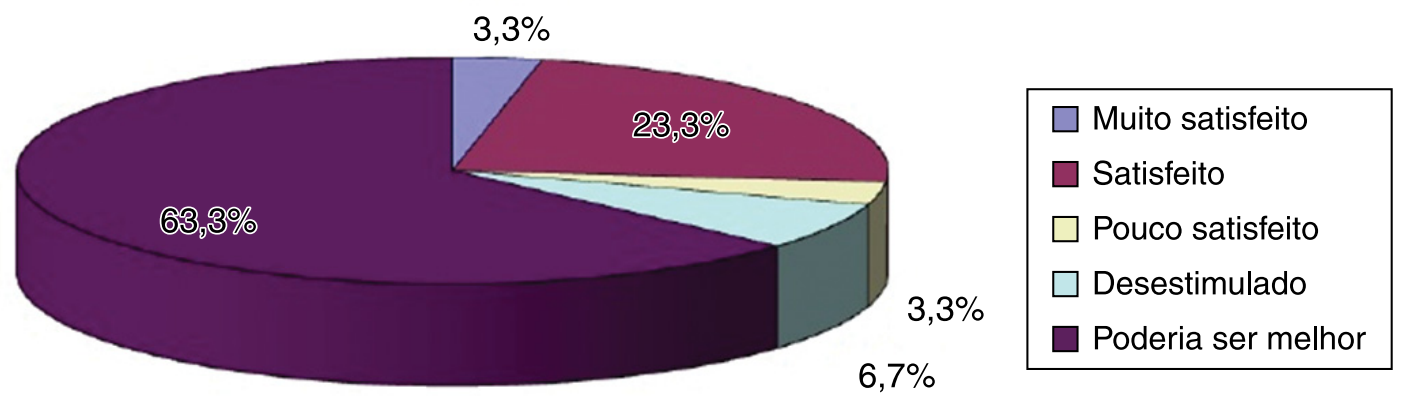

Figura 4. Distribuição das citações dos CDs relativas ao grau de satisfação com relação a suas funções.

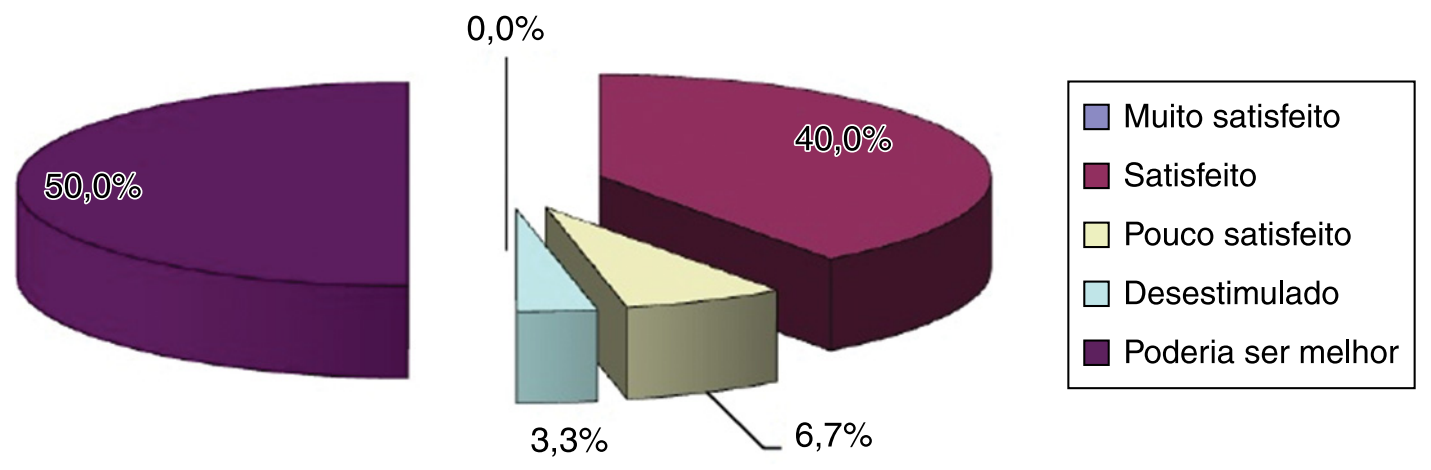

Figura 5. Distribuição das citações dos CDs relativas ao grau de satisfação com relação à ESF como um todo. 


\section{Conclusão}

De acordo com os resultados obtidos no presente estudo, pode-se concluir que o desenvolvimento do trabalho em equipe náo acontece de forma habitual, os $\mathrm{CD}$ s náo participam de forma integrada na equipe e, portanto, a articulação das açóes entre os membros da equipe não acontece de maneira sistemática, como parte integrante de seu processo de trabalho.

Os profissionais, de uma forma geral, mostraram-se insatisfeitos com o desempenho de suas funções na estratégia saúde da família, provavelmente em virtude da atual postura do município, no que diz respeito ao vínculo (estabilidade), às diferenças salariais entre categorias profissionais, baixos salários e falta de investimento na educação permanente da força de trabalho em saúde.

O trabalho em equipe corresponde a uma modalidade de trabalho coletivo em que há reciprocidade nas intervençóes, respeitando-se espaços, agregando-se valores humanos, éticos e técnicos.

Instabilidade na forma de contratação dos profissionais, insatisfação salarial, formas de tratamento e remuneração diferenciadas entre categorias profissionais são fatores desagregadores à ESF e ao SUS enquanto sistema de saúde, porque geram insatisfaçóes capazes de comprometer o trabalho em equipe e a atenção à saúde da população.

Grande parte dos profissionais ingressou na ESF sem nenhuma capacitação e só após algum tempo de serviço o município ofereceu algum curso que os habilitasse para essa modalidade de trabalho. Tal constatação, provavelmente reflete dificuldades na gestão e contribui para afetar a qualidade do serviço ofertado.

A maioria possui outros vínculos empregatícios, tanto no setor público como no privado, apesar das 40 horas semanais exigidas pelo Ministério da Saúde. $\mathrm{O}$ fato de não se dedicarem exclusivamente à ESF deve-se provavelmente à instabilidade dos profissionais no que diz respeito ao vínculo com o município, à necessidade de atuar em outros campos como forma de complementaçáo salarial ou até mesmo, à insatisfação com o trabalho e ao descompromisso com a ESF.

Desta forma, sugerimos um acompanhamento sistemático do processo de trabalho do CD integrante da ESF, no sentido de detectar quais motivos estão contribuindo para a baixa integração dos profissionais na equipe e sua insatisfação com o serviço de saúde, com a finalidade de prover as condiçóes necessárias para a resoluçáo dos problemas detectados no presente estudo e promover melhorias na qualidade dos serviços prestados à população.

\section{Referências}

1. Merhy EE, Franco TB. Por uma composição técnica do trabalho em saúde centrado no campo relacional e nas tecnologias leves. Apontando mudanças para os modelos tecno-assistenciais. Saúde debate. 2003; 27(65): 316-323.

2. Brasil. Secretaria de Assistência à Saúde. Coordenação de Saúde da Comunidade. Saúde da Família: uma estratégia para a reorientação do modelo assistencial. Brasília: Ministério da Saúde, 1997

3. Peduzzi M. Equipe multiprofissional de saúde: conceito e tipologia. Rev Saúde Públ. 2001; 35(1): 103-9. http://dx.doi.org/10.1590/S003489102001000100016

4. Araújo MBS, Rocha PM. Trabalho em equipe: um desafio para a consolidação da Estratégia de Saúde da Família. Ciênc Saúde Coletiva. 2007; 12(2): 455-464. PMid:17695079.

5. Souza TMS. A incorporação da Saúde Bucal no Programa Saúde da Família no Rio Grande do Norte: investigando a possibilidade de conversão do modelo assistencial. [Dissertação]. Natal: Universidade Federal do Rio Grande do Norte, 2005.

6. Franco T, Merhy E. PSF: Contradições e novos desafios. Conferência Nacional de Saúde. [online] [acesso em 2008 Fev 05]. Disponível em: http://www.datasus.gov.br/cns/cns.htm

7. Werneck MAF, Ferreira RC. Tecnologia em saúde bucal. In: Pinto VG, organizador. Saúde Bucal Coletiva. São Paulo: Santos; 2000. p. 277-286

8. Pires D. Reestruturação produtiva e conseqüências para o trabalho em saúde. Rev Bras Enferm. 2000; 53(5): 251-63. PMid:12138828.

9. Mattos RA. Em busca de novos projetos coletivos. Ciênc Saúde Coletiva. 1999; 4(2): 250-2.

10. Vilarinho SMM, Mendes RF, Prado Júnior RR. Perfil dos cirurgiõesdentistas Integrantes do Programa Saúde da Família em Teresina (PI). Rev Odonto Ciênc. 2007; 22(55): 48-54.

11. Cotta RMM. Organização do trabalho e perfil dos profissionais do Programa Saúde da Família: um desafio na reestruturação da atenção básica em saúde. Epidemiol Serv Saúde. 2006; 15(3): 7-18.

12. Araújo YP, Dimenstein M. Estrutura e organização do trabalho do cirurgião-dentista no PSF de municípios do Rio Grande do Norte. Ciênc Saúde Coletiva. 2006; 11(1): 219-27. http://dx.doi.org/10.1590/ S1413-81232006000100031

13. Facó EF, Viana LMO, Bastos VA, Nuto SAS. O Cirurgião-Dentista e o programa saúde da família na microrregião II, Ceará, Brasil. Rev Bras Promoção Saúde 2005; 18(2): 70-77.

14. Rodrigues MP, Araújo MSSA. O processo de trabalho em saúde da família.[online].[acesso em 2008 Mai 02]. Disponível em: www. observatório.nesc.ufrn.br

15. Volschan BCG, Soares EL, Corvino M. Perfil do profissional de saúde da família. Rev Bras Odontol. 2002; 59(5): 314-6.

16. Carvalho CL, Girardi SB. Agentes institucionais e modalidades de contratação de pessoal no Programa Saúde da Família no Brasil. Belo Horizonte: Núcleo de Pesquisa em Saúde Coletiva, Universidade Federal de Minas Gerais; 2002.

17. Moysés SJ, Silveira Filho AD. Saúde Bucal da Família: quando o corpo ganha uma boca. In: Moysés SJ, Silveira Filho, AD, Ducci L, editores. Os dizeres da boca em Curitiba: Boca Maldita, Boqueirão, Bocas saudáveis. Rio de Janeiro: CEBES; 2002 


\section{Anexo 1}

Bloco I

\section{Questionário}

1. Idade:

anos

\section{Sexo:}

$\square$ Masculino

$\square$ Feminino

\section{Estado Civil:}

$\square$ Solteiro

$\square$ Casado
Divorciado

Viúvo

\section{Graduação:}

Instituição:

Pública

Privada

Ano de conclusão:

UF:

\section{Pós-graduação:}

Doutorado/Área:

Mestrado/Área:

Especialização/Área:

\section{Há quanto tempo você concluiu o Curso de Odontologia?}

Menos de 5 anos

Entre 5 e 10 anos
De 10 a 15 anos

Mais de 15 anos

7. Há quanto tempo você trabalha no Programa, incluindo experiências anteriores:

Menos de 1 ano

Entre 1 e 2 anos
De 2 a 4 anos

Mais de 4 anos 
8. Independente da titulaçáo formal, marque a(s) área(s) em que se considera especialista, com base na própria experiência:

Dentística

Endodontia

Outras (especificar)
Odontopediatria

Periodontia

Nenhuma

\section{Residência atual:}

Cidade:

UF:

\section{Local de atuaçáo no Programa:}

Mesmo bairro ou equivalente na cidade onde reside

Outro bairro na cidade onde reside

Outra cidade

11. Acesso ao local de atuaçáo no Programa, utilizando o meio de transporte habitual:

Até $30 \mathrm{~min}$

De 30 min até $1 \mathrm{~h}$

Mais de $1 \mathrm{~h}$

12. A populaçáo de sua área de trabalho é:

Urbana

Rural

Mista

13. Registre a distribuiçáo de sua carga horária semanal no Programa naquelas atividades que exerce habitualmente:

\begin{tabular}{|l|l|l|}
\hline \multicolumn{1}{|c|}{ Tipos de atividades } & \multicolumn{1}{c|}{$\mathrm{N}^{0}$ horas trabalhadas } & Não realizo \\
\hline Consultório & & \\
\hline Atividades de grupo na Unidade de Saúde & & \\
\hline Atividades de grupo na comunidade & & \\
\hline Saúde Escolar & & \\
\hline Capacitação & & \\
\hline Estudos/pesquisas & & \\
\hline Atividades administrativas na Unidade & & \\
\hline Atendimento domiciliar & & \\
\hline Deslocamento para outras atividades fora da unidade de saúde & & \\
\hline
\end{tabular}

\section{Capacitaçáo em Saúde da Família antes de ingressar no Programa:}

$$
\text { Sim }
$$

Curso/Instituição:

Carga horária/ano de conclusão:

Curso/Instituição:

Carga horária/ano de conclusão: 


\section{Capacitaçáo em Saúde da Família após ingressar no Programa:}

Sim

Não

Curso/Instituição:

Carga horária/ano de conclusão:

Curso/Instituição:

Carga horária/ano de conclusão:

16. Experiência anterior em Saúde da Família:

$\operatorname{Sim}$

Não

\begin{tabular}{|c|c|c|}
\hline & UF & Tempo de atuação \\
\hline & & \\
\hline & & \\
\hline & & \\
\hline & & \\
\hline
\end{tabular}

17. Experiência profissional além de Saúde da Família:

No Setor Público:

\begin{tabular}{|l|l|l|l|}
\hline \multicolumn{1}{|c|}{ Atividade } & Tempo de atuação & \multicolumn{2}{|c|}{ Exerce atualmente? } \\
\hline Consultório & & Sim \\
\hline Hospital & & $\square$ \\
\hline Outra: & Sim & Sim \\
\hline Outra: & Sim & $\square$ \\
\hline
\end{tabular}

No Setor Privado:

\begin{tabular}{|l|l|l|l|}
\hline \multicolumn{1}{|c|}{ Atividade } & Tempo de atuação & \multicolumn{2}{c|}{ Exerce atualmente? } \\
\hline Consultório & & $\square$ \\
\hline Hospital & Sim & $\square$ \\
\hline Outra: & Sim & Sim \\
\hline Outra: & & $\square$ \\
\hline
\end{tabular}

18. Registre a distribuiçáo percentual aproximada de seus rendimentos:

\begin{tabular}{|l|l|}
\hline \multicolumn{1}{|c|}{ Fontes de rendimento } & $\%$ \\
\hline Remuneração do Programa & \\
\hline Outros rendimentos & \\
\hline Aposentadoria & 100 \\
\hline Total & \\
\hline
\end{tabular}




\section{BLOCO II}

19. Na realizaçáo de suas atividades no Programa, você busca a colaboraçáo de outro(s) integrante(s) da equipe além de sua ACD:

Habitualmente

Ocasionalmente

Não

20. Os outros integrantes da equipe buscam sua colaboraçáo na realizaçáo das respectivas atividades no Programa: Habitualmente

Ocasionalmente Não

20. Assinale, para cada atividade abaixo, com que frequência atua em colaboraçáo com outro(s) integrante(s) da equipe:

\begin{tabular}{|l|l|l|l|}
\hline \multicolumn{1}{|c|}{ Tipos de atividades } & 1-Habitualmente & 2-Ocasionalmente & 3-Não \\
\hline Consulta na unidade & & & \\
\hline Visita domiciliar & & & \\
\hline Atividade em grupo na Unidade & & & \\
\hline Atividades na comunidade & & & \\
\hline Saúde Escolar & & & \\
\hline Atividades administrativas & & & \\
\hline Outra: & & & \\
\hline
\end{tabular}

21. Assinale se participa do atendimento das seguintes clientelas e estime a distribuiçáo percentual de atendimento no consultório da unidade de saúde, segundo os grupos listados abaixo:

\begin{tabular}{|l|l|l|l|}
\hline \multicolumn{1}{|c|}{ Clientela } & \multicolumn{1}{|c|}{ 1-Sim } & & \multicolumn{1}{c|}{ 2-Não } \\
\hline Gestantes & & & \\
\hline Crianças $\leq 4$ anos & & & \\
\hline Crianças $>4$ anos & & & \\
\hline Adolescentes & & & \\
\hline Adultos & & & \\
\hline Idosos & & & \\
\hline Hipertensos & & & \\
\hline Diabéticos & & & \\
\hline Portadores Necessidades Especiais & & & \\
\hline Outro: & & & \\
\hline Outro: & & & \\
\hline
\end{tabular}

22. Assinale com que periodicidade a equipe se reúne:

Semanal

Quinzenal

Mensal
Não tem periodicidade definida

De acordo com a necessidade da equipe

Não se reúne

23. Caso a equipe se reúna, assinale a duração média das reuniốes:

Até $1 \mathrm{~h}$

Até $2 \mathrm{~h}$
Até $3 \mathrm{~h}$

Uma manhã ou uma tarde 
24. Quem coordena habitualmente essas reunióes:

Médico

Enfermeiro

Odontólogo
Outro:

Um dos integrantes, rotativamente

25. Você participa dessas reunióes:

Habitualmente

Ocasionalmente

Não participa

26. Em sua opiniáo, em que medida essas reunióes contribuem para maior efetividade do trabalho da equipe:

Muito

Um pouco
Não contribui

Não sei

27. Assinale como é elaborada a programaçáo das atividades da equipe:

Cada um elabora sua parte

Em conjunto com toda equipe

Pelo coordenador da equipe
Pelo administrador da unidade

Pelo coordenador do Programa

Outro:

28. Você recebe algum tipo de supervisão na realizaçáo de suas atividades?

$\operatorname{Sim}$

Não

29. O Programa realiza reunióes do nível central com a equipe?

Sim

$\square$ Não

30. Em caso afirmativo, qual é a periodicidade dessas reunióes?

Semanal

Mensal
Quinzenal

Não tem periodicidade definida

31. Você exerce atualmente, ainda que de maneira informal, a coordenaçáo da equipe?

$\operatorname{Sim}$

Não

32. Ordene, numa escala de 1 a 5 a importância relativa que você atribui aos seguintes fatores para melhorar os resultados do Programa:

\begin{tabular}{|l|l|}
\hline \multicolumn{1}{|c|}{ Fator } & Importância relativa \\
\hline Capacitação dos integrantes da equipe & \\
\hline Organização do trabalho em equipe & \\
\hline Sistema de referência e contrarreferência & \\
\hline Outro: & \\
\hline Outro: & \\
\hline Outro: & \\
\hline
\end{tabular}


BLOCO III

33. Como você disponibiliza o acesso dos pacientes ao consultório?

Agendamento

Demanda livre
Através de fichas distribuídas na Unidade

Outro:

34. Caso você trabalhe com agendamento, de que forma você o realiza?

Agendamento diário

Agendamento mensal
Agendamento semanal

Outro:

35. Qual sequência abaixo você dá prioridade de atendimento ?

Só por ordem de chegada ou hora marcada

Pacientes especiais (idosos, gestantes, etc.), urgência e ordem de chegada

Urgência, pacientes especiais (idosos, gestantes, etc.) e ordem de chegada

Outro:

36. Você se sente seguro com relaçáo a todos os procedimentos clínicos realizados, uma vez que o CD do PSF assume um perfil generalista?

Sim

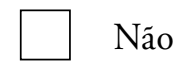

37. Quais a(s) área(s) em que você acha necessário haver permanente capacitação?

Dentística

Atividades coletivas

Periodontia $\square$ Cirurgia

$\square$ Paciente especiais

$\square$ Outra:

38. Você costuma buscar opinióes de especialistas quando atende os usuários do Programa?

Sim

Não

39. Assinale os meios que o Programa oferece para ouvir a opiniáo de especialistas:

Telefone

Nenhum

Encaminho logo para o serviço especializado 
40. Você dispóe de algum serviço de referência para encaminhar pacientes para realizaçáo de procedimentos especializados?

$\operatorname{Sim}$

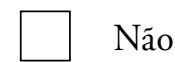

41. Assinale com que frequência encaminha pacientes para cada uma das especialidades abaixo:

\begin{tabular}{|l|l|l|l|}
\hline \multicolumn{1}{|c|}{ Especialidade } & 1-Habitualmente & 2-0casionalmente & 3-Não \\
\hline Endodontia & & & \\
\hline Periodontia & & & \\
\hline Odontopediatria & & & \\
\hline Cirurgia & & & \\
\hline Prótese & & & \\
\hline Pacientes Especiais & & & \\
\hline Outro: & & & \\
\hline
\end{tabular}

42. Você acha que o Serviço poderia oferecer outra(s) especialidade(s), além das que já oferece?

Sim

Náo

43.Em sua opinião, qual(is) seria(m) esta(s) especialidade(s)?

Ortodontia

Prótese fixa

Outra:

Nenhuma

44. Depois do encaminhamento de pacientes ao especialista, você recebe algum retorno do atendimento (contrarreferência)?

Frequentemente

Raramente

Não

45. De um modo geral, você acha que os mecanismos de contrarreferência funcionam?

Adequadamente

Não funcionam

Precariamente

Não sei

46. O Programa oferece os EPIs necessários para a realizaçáo de qualquer procedimento clínico que você habitualmente realiza?

Frequentemente

Sempre

Ocasionalmente

Raramente

47. Você atende pacientes portadores de doenças infectocontagiosas graves (Hepatite B e C, HIV), caso este relate ser portador?

Não me sinto preparado

Encaminho ao serviço especializado
Sim, com os EPIs adequados

Não, mesmo com os EPIs 
48. Você possui algum curso de capacitaçáo para atendimento clínico a portadores de doenças infectocontagiosas? $\operatorname{Sim}$

Não

49. Estime um percentual das atividades abaixo que você exerce rotineiramente no consultório?

\begin{tabular}{|l|l|l|l|}
\hline \multicolumn{1}{|c|}{ Atividades } & \multicolumn{1}{|c|}{ Nõo realizo } & Não realizo por falta de condições materiais \\
\hline Dentística & & & \\
\hline Exodontia & & & \\
\hline Periodontia & & & \\
\hline Aplic. Tópica de flúor & & & \\
\hline OHB & & & \\
\hline Profilaxia & & & \\
\hline Outra: & & & \\
\hline Outra: & & & \\
\hline
\end{tabular}

50. Assinale com que frequência você realiza as atividades abaixo relacionadas, fora da Unidade:

\begin{tabular}{|l|l|l|l|l|}
\hline \multicolumn{1}{|c|}{ Atividades } & Frequentemente & Raramente & Ocasionalmente & Não realizo \\
\hline Ed. em saúde na comunidade & & & & \\
\hline Ed. Em saúde na escola & & & & \\
\hline Participação em reuniões com comunidade & & & & \\
\hline Participação em reuniões escolares & & & & \\
\hline Reuniões com grupos de hipertensos, diabéticos, gestante, etc. & & & & \\
\hline Aplicação coletiva de flúor & & & & \\
\hline Bochechos e escovação supervisionada & & & \\
\hline Visitas domiciliares & & & & \\
\hline Exames bucais com finalidade epidemiológica & & & \\
\hline
\end{tabular}

\section{BLOCO IV}

51. Você dispóe de um diagnóstico dos problemas de saúde e dos fatores de risco mais importantes na sua área de atuação?

Sim

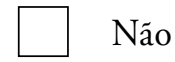

52. Em caso afirmativo, você participou ou participa da elaboraçáo deste trabalho?

$\operatorname{Sim}$

Não

53. Sua equipe trabalha preventivamente junto com a comunidade, em datas específicas, temas referentes a doenças como: Diabetes, Hipertensão, Câncer, etc.?

Sim

Não

54. Em caso afirmativo, você participa destes eventos?

Sim

Não 
55. Há um planejamento de açóes a serem realizadas na unidade de saúde ou mesmo fora da unidade feito pela equipe, para realização de tais eventos?

$\operatorname{Sim}$

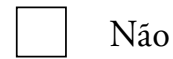

56. Em caso afirmativo, qual a periodicidade com que é feito este planejamento?

Planejamento anual

Planejamento semestral

$\mathrm{Na}$ semana anterior

Planejamento mensal

57. De que forma estas datas importantes são escolhidas para serem trabalhadas?

Existe na unidade um calendário informando tais datas

Trabalhamos de acordo com a necessidade da populaçáo

Trabalhamos de acordo com o que a equipe decidir sem olhar datas

Escolhemos aleatoriamente um tema para ser trabalhado

58. Qual o grau de satisfaçáo que você encontra na realização de suas funçóes dentro do Programa?

Satisfeito

Pouco satisfeito

Poderia ser melhor em alguns aspectos
Muito satisfeito

Desestimulado

Outro:

59. Qual o grau de satisfaçáo que você encontra com relaçáo ao Programa como um todo?

Satisfeito

Pouco satisfeito

Poderia ser melhor em alguns aspectos
Muito satisfeito

Desestimulado

Outro: 